\title{
Fatores Determinantes da Divulgação de Informações Voluntária Social: Evidências Empíricas no Brasil
}

\begin{abstract}
Resumo
A responsabilidade social corporativa se refere às preocupações sociais relacionadas ao meio ambiente, aos recursos humanos e ao envolvimento com a comunidade. A divulgação voluntária de informações sociais ocorre de forma heterogênea e algumas empresas optam por evidenciar uma quantidade maior de informações e com maior riqueza de detalhes. Ciente disso, esta pesquisa teve como objetivo identificar os fatores determinantes da divulgação voluntária de informações de caráter social das empresas brasileiras, no período de 2010 a 2012. A partir das teorias (stakeholders e divulgação voluntária) e dos estudos anteriores, construíram-se seis hipóteses sobre os possíveis fatores determinantes da divulgação voluntária social (tamanho, concentração acionária, rentabilidade, leverage, setor regulado e reputação). O universo desta pesquisa foram as empresas de capital aberto listadas na BM\&FBOVESPA, no período de 2010 a 2012. A amostra foi composta pelas 100 empresas listadas na BM\&FBovespa com ações mais negociadas durante os 12 meses do ano de 2012. Quanto aos modelos econométricos, utilizou-se painel com efeitos aleatório estimado por OLS, sendo a variável dependente os índices de divulgação social e as variáveis independentes, os prováveis fatores determinantes. Os resultados sugeriram que o tamanho da empresa, a rentabilidade, a reputação e o setor regulado foram fatores considerados determinantes da divulgação voluntária social. Constatou-se que os stakeholders, o governo e a sociedade podem influenciar a divulgação voluntária social. A variável "rentabilidade" aponta que as empresas menos rentáveis divulgaram mais informações voluntárias sociais, o que pode ser indício de uma tentativa da empresa de desviar a atenção dos stakeholders do desempenho financeiro.
\end{abstract}

Palavras-chaves: Fatores Determinantes, Divulgação Voluntária Social, Empresas Brasileiras.

\begin{abstract}
Maria Audenôra Rufino
Mestre em Ciências Contábeis pelo Programa Multiinstitucional e Interregional de Pós-graduação em Ciências Contábeis UnB/UFPB/UFRN e professora do Centro Universitário de João Pessoa (Unipê). Contato: BR 230 KM 22, Campus do Unipê, Água Fria, João Pessoa-PB, CEP: 58053-000.

E-mail: maryaudenora@hotmail.com
\end{abstract}

\section{Márcia Reis Machado}

Doutora em Controladoria e Contabilidade pela USP e professora da Universidade Federal da Paraíba (UFPB). Contato: Jardim Cidade Universitária, Campus Universitário I, Castelo Branco, João Pessoa-PB, CEP: 58059-900.

E-mail: marciareism@hotmail.com 


\section{Introdução}

Por muito tempo, as empresas foram vistas como entidades econômicas cujo único propósito era produzir resultados financeiros que satisfizessem aos acionistas, por meio da remuneração do capital. Mas essa visão tradicional não se aplica ao mundo contemporâneo, no qual as empresas não se resumem apenas a remunerar o capital investido, visto que, sem os recursos naturais, direto ou indiretamente, e sem o capital humano, não se gera riqueza. A política de responsabilidade social corporativa de uma empresa identifica as preocupações sociais relacionadas ao meio ambiente, aos recursos humanos, ao envolvimento com a comunidade e à segurança dos produtos (Roberts, 1992).

Conforme Oliveira (2005), a responsabilidade social diz respeito à maneira como as empresas agem, como impactam e como se relacionam com o meio ambiente e suas partes legitimamente interessadas (os chamados stakeholders). É um conceito segundo o qual as organizações, ao tomarem decisões, consideram as necessidades de todas as partes envolvidas, como: clientes, funcionários, fornecedores, acionistas, comunidade, ambientalistas e governo (Reverte, 2009, Deegan, Rankin \& Tobin, 2012).

A divulgação das informações corporativas e o reconhecimento de informações econômicas são apenas uma parte das atribuições empresariais, e isso precisa ser, no mínimo, complementado pelo reconhecimento das práticas sociais e ambientais. No Brasil, a divulgação dos aspectos sociais e ambientais ainda se dá de forma voluntária. Nesse sentido, a responsabilidade social corporativa refere-se à contribuição voluntária de uma empresa para o desenvolvimento sustentável, que vai além das exigências legais (Gamerschlag, Möller \& Verbeeten, 2011).

A divulgação pode ocorrer dentro de duas perspectivas: obrigatória e voluntária. A divulgação obrigatória é proveniente de alguma regulamentação que especifica os requisitos mínimos considerados aceitáveis de evidenciação informacional (Dahlsrud, 2008), enquanto a divulgação voluntária remete a itens que são divulgados de forma optativa pela empresa, portanto, estão acima do nível de divulgação regulamentada por alguma entidade governamental. Devido à natureza discricionária da divulgação, muito se questiona quais são as características (fatores - características quantitativas e qualitativas) das empresas que poderiam explicar o comportamento ou a preocupação em desenvolver e, consequentemente, divulgar as práticas de responsabilidade social.

Associada a isso, a divulgação voluntária social não ocorre de forma homogênea, sendo que algumas empresas optam por evidenciar uma quantidade maior de informações e com maior riqueza de detalhes. Portanto, este estudo questionou: Quais os fatores determinantes da divulgação voluntária das informações de caráter social?

Esta pesquisa teve o objetivo geral de identificar os fatores determinantes da divulgação voluntária de informações de caráter social das empresas brasileiras, no período de 2010 a 2012.

A responsabilidade social tem sido objeto de divulgação, não podendo a contabilidade ficar à margem desse processo (Eugénio, 2010). Nesse contexto, esta pesquisa é uma tentativa de aumentar o entendimento acerca das práticas e da divulgação voluntária de informações sociais nos relatórios anuais e afins, e da ampliação do conhecimento dos fatores que explicam a referida divulgação social. Os gestores necessitam compreender e participar ativamente das mudanças estruturais que estão ocorrendo na área social. Essa é uma questão relevante, porque a compreensão dos fatores que influenciam a divulgação voluntária pode possibilitar o entendimento de como a responsabilidade social é enxergada, compreendida ou utilizada pelas empresas. Além dos expostos anteriores, esse trabalho traz uma posição sobre a relação entre rentabilidade e divulgação voluntária social, visto que as relações observadas nos estudos anteriores se mostram bidimensionais, podendo ser positivas ou negativas.

Este artigo encontra-se estruturado em sete capítulos: Introdução; Teoria dos Stakeholders; Teoria da Divulgação Voluntária; Formulação das Hipóteses de Pesquisa; Metodologia; Apresentação e Análise dos Resultados; e Considerações Finais. 


\section{Teoria dos Stakeholders}

A teoria dos Stakeholders é de gestão organizacional ética (Phillips, Freeman \& Wicks, 2003) e gerencial, que não se limita a descrever as situações existentes ou prever relações causa-efeito, mas também recomenda atitudes planejadas e práticas que, em conjunto, constituem o gerenciamento dos stakeholders. O gerenciamento dos stakeholders requer, como principal atributo, atenção simultânea aos interesses legítimos de todas as partes interessadas, tanto no estabelecimento de estruturas organizacionais e políticas quanto no caso da tomada de decisão.

Sobre isso, Clarkson (1995) afirma que a sobrevivência e o sucesso contínuo de uma empresa dependem da capacidade de seus administradores para criar riqueza, valor ou satisfação para os grupos de stakeholders, de modo que cada grupo continue a fazer parte do sistema da empresa. Nesse sentido, a teoria, em visão geral, reconhece a importância de se tomar decisões gerenciais embasadas nos interesses das partes, que podem afetar ou ser afetada pela execução do objetivo da empresa.

A visão gerencial da teoria dos Stakeholders envolve atenção que vai além de maximização da riqueza dos acionistas, mas se preocupa com a aceitação dos outros grupos que possuem, direta ou indiretamente, potenciais de ajudar ou dificultar a realização dos objetivos da empresa (Phillips, Freeman \& Wicks, 2003). As empresas precisam considerar as necessidades das partes interessadas quando da elaboração das estratégias corporativas, caso contrário, os Stakeholders podem retirar o apoio dado à atividade da empresa (Huang \& Kung, 2010).

Os Stakeholders tendem a se identificar com as empresas quando percebem que seus próprios valores combinam com os atributos corporativos. Nesse contexto, a integração de princípios de responsabilidade social e ambiental corporativa, dentro da cultura organizacional, pode ajudar as empresas a reforçarem a relação com os stakeholders. Essa teoria busca explicar os efeitos diretos que as partes interessadas têm sobre as decisões gerenciais e as atividades das empresas.

Além disso, a teoria dos Stakeholders, entre outras questões, discute a capacidade da empresa de equilibrar as demandas conflitantes dos diferentes stakeholders da empresa. O equilíbrio ou o desequilíbrio pode ser consequência do planejamento empresarial e do modelo político de negócio. Sendo assim, a empresa é moralmente responsável por organizar as atividades sociais de maneira que encontre um equilíbrio entre as demandas conflitantes dos stakeholders (Huang \& Kung, 2010).

A teoria dos Stakeholders tece seus argumentos sob a existência de poder ou a capacidade que os Stakeholders possuem de coagir as decisões dos gestores. Nesse caso, remete à decisão de desenvolver e divulgar informações voluntárias sobre aspectos sociais. A teoria fornece uma direção que integra a suposição acerca das atividades de responsabilidade social corporativa e o modelo de divulgação da responsabilidade social corporativa, sendo uma abordagem viável para explicar e prever o comportamento da gestão (Roberts, 1992).

Essa teoria considera claramente o impacto das expectativas dos diferentes grupos de Stakeholders existentes dentro da sociedade sobre a política de divulgação corporativa. Sobre o contexto gerencial da teoria, a divulgação corporativa é uma ferramenta de gestão para gerenciar as necessidades informacionais dos vários grupos Stakeholders (empregados, acionistas, investidores, consumidores, autoridades públicas, organizações não governamentais, entre outros) (Reverte, 2009).

Devido à influência que os Stakeholders podem exercer sobre a empresa, as organizações devem considerar a necessidade de modificar suas atividades, em vista de minimizar o conflito de interesses entre os indivíduos ou grupo de indivíduos que afetam ou são afetados pela operacionalização das atividades. Nesse sentido, a divulgação social é percebida como uma ferramenta que as empresas podem utilizar para responder aos anseios dos diferentes Stakeholders, sendo, portanto, um meio de comunicação entre as empresas e seus Stakeholders (Huang \& Kung, 2010).

A teoria dos Stakeholders fornece um substrato relevante para a existência da responsabilidade social nas empresas e, consequentemente, a adoção de práticas de divulgação de suas atividades sociais e ambientais (Nascimento, Santos, Salotti \& Murcia, 2009). Dentro da perspectiva da teoria, a divulgação 
de informações voluntárias sociais e ambientais é vista como uma estratégia que a empresa utiliza para gerenciar a percepção dos diversos grupos de interesse que se relacionam com a empresa, seja direta ou indiretamente. Sobre isso, Ceretta, Barba, Kruel e Milani (2009) afirmam que essa teoria postula que os gestores devem tomar decisões que levem em conta os interesses de todos os Stakeholders da empresa.

Nesta pesquisa, a teoria dos Stakeholders foi utilizada para explicar como os Stakeholders e seus interesses conflitantes são geridos pelas empresas, por meio da divulgação da responsabilidade social e ambiental. A divulgação é vista como parte do diálogo entre as empresas e seus Stakeholders. Assim sendo, a teoria dos Stakeholders fornece a sustentação para explicar a divulgação dos aspectos sociais pela gestão da empresa, visto que a influência de acionistas, clientes, governo, sociedade, financiadores foi testada como possível fator determinante da divulgação das informações sociais.

\section{Teoria da Divulgação Voluntária}

A teoria da Divulgação Voluntária postula que as empresas com "boas notícias" têm incentivos para divulgar, a fim de evitar o problema de seleção adversa. No Brasil, as principais pesquisas empíricas que utilizaram a teoria da divulgação como fundamentação teórica foram: Cunha e Ribeiro (2008); Braga, Oliveira e Salotti (2009); Murcia e Santos (2009); Rover, Borba e Murcia (2009); Rover, Tomazzia, Murcia e Borba (2012); Silva e Pinheiro (2012).

A divulgação, de acordo como Verrecchia (2001), pode ser baseada em associação (association-based disclosure), em eficiência (efficiency-based disclosure) ou em julgamento (discretionary-based disclosure). A primeira examina os efeitos da divulgação sobre as ações cumulativas dos indivíduos, enquanto agentes investidores, no momento da divulgação. A segunda discute as modalidades preferidas de divulgação na ausência de conhecimento prévio da informação, ou seja, as preferências incondicionais. E, por último, a divulgação baseada em julgamento analisa a discricionariedade das informações que os gestores praticam no que se refere às decisões de divulgação.

O processo de divulgação passa a ser a característica que diferencia a categoria "associação" da categoria "julgamento". Na primeira, não se discutem os motivos da empresa, isto é, o processo de divulgação é exógeno, porém, na segunda, esses motivos passam a ser considerados (processo endógeno), e, dessa forma, questiona-se por que a firma divulgaria, ou não, determinadas informações (Salotti \& Yamamoto, 2005).

A divulgação baseada na discricionariedade compreende pesquisas que identificam quais os motivos da divulgação, ou seja, procuram examinar como os gestores e/ou as empresas decidem divulgar determinadas informações, nesse sentido, a divulgação é um processo endógeno, considerando os incentivos que os gestores e/ou as empresas têm para divulgar as informações (Salotti \& Yamamoto, 2005).

$\mathrm{Na}$ divulgação das informações corporativas, geralmente, o reconhecimento de informações econômicas são apenas uma parte das atribuições empresariais, e isso precisa ser, no mínimo, complementado pelo reconhecimento de práticas sociais e ambientais. O balanço social, o relatório de sustentabilidade ou o relatório anual são demonstrações em ambiente não regulamentado que possibilitam, entre outras coisas, a divulgação dos investimentos sociais e ambientais. Magness (2006) cita que os relatórios anuais podem e devem ser utilizados para divulgar informações de natureza social, objetivando legitimar as atividades.

\section{Formulação das Hipóteses de Pesquisa}

Com base nos estudos anteriores de Hackston e Milne (1996), Choi (1999), Jennifer Ho e Taylor (2007), Branco e Rodrigues (2008), Cunha e Ribeiro (2008), Gamerschlag, Möller e Verbeeten (2011), Lu e Abeysekera (2014) e na perspectiva multiteórica, construíram-se as hipóteses que estão associadas às características, sejam quantitativas ou qualitativas, das empresas que podem explicar o nível de divulgação de informações voluntárias sociais. 
A interação das grandes empresas com a sociedade tende a ser mais frequente e com maior importância econômica, promovendo elevada visibilidade diante do público. Sendo assim, quanto maior o tamanho da empresa, maior é o seu comprometimento com o meio ambiente ou, pelo menos, maior é a sua preocupação em demonstrar esse comprometimento (Costa \& Marion, 2007). Além disso, os custos associados à divulgação em geral podem ter uma representatividade menor para as grandes empresas (Jennifer Ho \& Taylor, 2007). Sobre isso, a premissa central da divulgação voluntária, segundo Dye (2001), postula que somente ocorre a divulgação quando os benefícios são maiores que os custos associados à divulgação.

A associação entre o tamanho da empresa e o nível de divulgação voluntária de caráter social foi demonstrada por alguns estudos empíricos. Os resultados das pesquisas de Hackston e Milne (1996), Jennifer e Taylor (2007), Cunha e Ribeiro (2008) e Lu e Abeysekera (2014) mostraram que o tamanho da empresa estaria consistentemente associado ao nível de divulgação voluntária social.

Para operacionalizar a hipótese, foi utilizado, como medida, o logaritmo natural do ativo total dos respectivos períodos investigados. Assim, formula-se a seguinte hipótese de pesquisa:

Hipótese 1 - as empresas maiores divulgam mais informações voluntárias de natureza social do que as empresas menores.

Evidências sugerem que a dispersão da propriedade acionária com muitos investidores, alguns podendo ter preocupações significativas acerca dos impactos ambientais da empresa, pode aumentar o nível de divulgação (Cullen \& Christophor, 2002). Além disso, quando a propriedade é relativamente difundida, a ausência de divulgação aumenta a assimetria informacional entre a organização e seus acionistas (Brammer \& Pavelin, 2008). Contrariamente, as empresas com uma estrutura de propriedade concentrada são menos motivadas a divulgar informações adicionais sobre a sua responsabilidade social, porque seus acionistas podem obter informações diretamente na empresa.

A hipótese concentração acionária (estrutura da propriedade) foi operacionalizada utilizando a mesma proxy do estudo de Lu e Abeysekera (2014): o percentual de participação acionária, com direito a voto, do principal acionista da empresa. Dessa forma, tem-se a seguinte hipótese de pesquisa:

Hipótese 2 - as empresas com menor concentração acionária divulgam mais informações voluntárias de natureza social do que as empresas com maior concentração acionária.

Estudos baseados principalmente na teoria dos Stakeholders pressupõem uma relação positiva entre a política de divulgação social e a rentabilidade das empresas. Porém, os achados mostraram que a associação entre divulgação social e a rentabilidade da empresa produziram resultados variados. O estudo de Ameer e Othman (2012) defende que há relação bidirecional entre práticas de responsabilidade social corporativa e a rentabilidade das empresas. Contrariamente, a pesquisa de O'Dwyer (2003) encontrou evidências de uma tendência para os gestores interpretarem a responsabilidade social corporativa como algo pouco consistente aos objetivos das empresas irlandesas, que é a maximização da riqueza dos acionistas. Todavia, a discricionariedade da divulgação pode ser explicada a partir da necessidade das empresas de reduzir a assimetria informacional.

Para medir essa relação, foi utilizada a proxy índice de retorno sobre o patrimônio líquido, derivado da relação entre o lucro líquido do exercício e o patrimônio líquido médio. Essa proxy foi amplamente utilizada por pesquisas empíricas para correlacionar a rentabilidade a outras variáveis. Exemplo de estudos que utilizaram essa proxy: Cunha e Ribeiro (2008); Hackston e Milne (1996); Chang e Kuo (2008), Wang, Sewone Claiborne (2008), Branco e Rodrigues (2008). Desse modo, formula-se a seguinte hipótese de pesquisa:

Hipótese 3 - as empresas que apresentam melhor rentabilidade divulgam mais informações voluntárias de natureza social do que as empresas com nível mais baixo de rentabilidade. 
A teoria dos Stakeholders tenta explicar os efeitos diretos que as partes interessadas (acionistas, empregados, clientes, fornecedores, credores e sociedade) têm sobre ações de divulgação das empresas. Brammer e Pavelin (2008) argumentam que o baixo grau de leverage em uma empresa leva os credores a desempenharem menos pressão para o desenvolvimento de atividades ligadas à responsabilidade social corporativa, porque estarão mais interessados em ampliar o retorno financeiro. Sobre isso, o estudo de Belkaoui e Karpik (1989) encontrou uma associação negativa entre a divulgação de informações sociais e o índice de leverage.

No entanto, pesquisas mais recentes, como as de Wang, Sewon e Caiborne (2008), Brammer e Pavelin (2008) e Jennifer Ho e Taylor (2007), não encontraram qualquer indício significativo de que o leverage é um importante determinante da divulgação social e/ou ambiental. De acordo com o trabalho de Reverte (2009), o leverage parece não explicar as diferenças nas práticas de divulgação da responsabilidade social nas empresas espanholas.

Para operacionalizar a hipótese, a variável foi modelada pelo indicador de leverage utilizado por Belkaoui e Karpik (1989); Brammer e Pavelin (2008); Branco e Rodrigues (2008); e Lu e Abeysekera (2014), derivado da relação entre o passivo exigível e o ativo total do período estudado. De tal modo, formula-se a seguinte hipótese de pesquisa:

Hipótese 4 - as empresas que possuem menor índice de leverage tendem a divulgar mais informações voluntárias de natureza social do que as empresas com maior índice de leverage.

A teoria dos Stakeholders assume a perspectiva de que o governo tem a capacidade de influenciar a estratégia da empresa por meio da regulamentação (Roberts, 1992). Na presente pesquisa, a regulamentação é interpretada como sendo as regras específicas de organismos governamentais as quais alguns setores estão sujeitos.

A variável regulamentação busca verificar se o Stakeholder governo exerce influência sobre o nível de divulgação voluntária social, por meio da regulamentação. Essa influência pode ocorre quando da recomendação e orientação do governo acerca das ações de responsabilidade social das empresas sujeitas à regulamentação. Liu e Anbumozhi (2009) descobriram que o governo chinês teve influência positiva e significativa sobre a divulgação ambiental das empresas daquele país. O estudo de Murcia e Santos (2009) mostrou que as empresas regulamentadas (setor de energia elétrica) divulgaram mais informações voluntárias do que as demais empresas de capital aberto. Porém, a pesquisa de Lu e Abeysekera (2014) não encontrou uma associação significativa entre o poder do governo e a divulgação social e ambiental.

O estudo de Kirch, Lima e Terra (2012) utilizou os setores de energia elétrica, finanças e seguros, mineração, petróleo e gás, telecomunicações e transportes para modelar à variável setor regulado. Assim sendo, para operacionalizar a variável "setor regulado", foi utilizada uma variável dicotômica, com valor 1 para as empresas pertencentes a setor regulado pelo governo, e valor 0 para as empresas não pertencentes a setor regulado. Assim, tem-se a seguinte hipótese de pesquisa:

Hipótese 5 - as empresas regulamentadas pelo governo divulgam mais informações voluntárias de caráter social do que as empresas não regulamentadas.

A divulgação de informações sobre a responsabilidade social contribui para a construção de uma imagem positiva da empresa para os Stakeholders (Branco \& Rodrigues, 2008), porque a divulgação pode influenciar a percepção da sociedade sobre a reputação da empresa.

A adequação às práticas de responsabilidade social é importante, porém a sociedade precisa ser informada sobre as ações da empresa, pois, se a divulgação não ocorre, a legitimidade pode não ser alcançada ou mantida. Nesse sentido, a divulgação é que confere à empresa o status de legítima (Villiers \& Staden, 2006). Assim, busca-se verificar se as empresas com melhor reputação divulgam mais informações voluntárias de caráter sociais. 
Para operacionalizar a hipótese "reputação", foi utilizada uma variável binária, com o valor 1 para as empresas que estão listadas no ranking das 100 empresas com melhor reputação, e 0 para as empresas que não estão inclusas no ranking. O ranking é o resultado de uma pesquisa divulgada exclusivamente pela revista Exame. Para se chegar às empresas que compõem o ranking da melhor reputação, a Merco e o Ibope reuniram dados econômicos das empresas e consultaram 450 executivos, 259 analistas de mercado e 1.000 consumidores. Assim, elabora-se a seguinte hipótese de pesquisa:

Hipótese 6 - as empresas que possuem melhor reputação divulgam mais informação voluntária de natureza social do que as empresas que não têm uma boa reputação.

\section{Metodologia}

Esta pesquisa buscou investigar os fatores determinantes da divulgação de informações voluntárias de caráter social, entre 2010 e 2012, nas empresas com ações mais negociadas na Bolsa de Valores, Mercadorias e Futuros de São Paulo (BM\&FBOVESPA). No primeiro estágio da pesquisa, foi necessário estabelecer os fatores determinantes da divulgação voluntária social.

Esta pesquisa é classificada como teórico-empírica, por verificar, mediante argumentos teóricos, os fatores determinantes da divulgação voluntária das informações de natureza social desenvolvidas pelas empresas, além de buscar encontrar relação entre as características das organizações e fatores que podem ser determinantes à divulgação voluntária de informações de natureza social. Isso é possível quando do estudo da relação entre as variáveis, como: tamanho, concentração acionária, rentabilidade, leverage, setor regulado e reputação.

Os dados quantitativos e qualitativos necessários para realizar a pesquisa foram extraídos de relatórios de sustentabilidade ou de demonstrativos afins. Posteriormente, os dados qualitativos foram quantificados para a obtenção do índice de divulgação voluntária. O contexto a ser pesquisado foram os relatórios anuais (RAs) ou relatórios afins, entre os anos de 2010 a 2012. Os relatórios foram obtidos por meio de busca eletrônica, com a consulta nos sítios das empresas. É salutar informar que, nesta pesquisa, o termo "relatório anual" é entendido como sinônimo de relatório de sustentabilidade, relatório socioambiental ou outros termos utilizados pelas empresas para designar o instrumento de divulgação das informações sociais e ambientais.

Quanto à técnica de coleta de informações, optou-se por análise de conteúdo, que estuda e analisa a comunicação de maneira objetiva e sistêmica. A técnica de coleta de informação - análise de conteúdo - foi utilizada para descrever as tendências no contexto da divulgação, identificando e interpretando as informações voluntárias divulgadas pelas empresas que desenvolvem e publicam práticas de responsabilidade social.

A análise de conteúdo é uma técnica de avaliação quantitativa de dados qualitativos que permite uma análise textual, a qual se caracteriza por dois momentos específicos: a identificação de informações sociais divulgadas pelas empresas e a classificação da sentença, de acordo com a métrica previamente estabelecida. A análise de conteúdo pode apresentar algumas limitações, por exemplo: risco de viés interpretativo do pesquisador quando da obtenção das informações (Wilmshurst \& Front, 2000); e diferente extensão da divulgação. Para reduzir o efeito do viés interpretativo, as informações extraídas dos relatórios foram realizadas por um único indivíduo. Assim, os possíveis vieses tiveram o mesmo peso para todas as empresas.

Os itens da métrica foram os mesmos utilizados por Rover e Santos (2013). A tabulação da análise de conteúdo seguiu os procedimentos: atribuiu-se o valor 1 para o item divulgado pela empresa e 0 para o item não divulgado. Posteriormente foi obtida a razão entre a soma dos itens divulgados e os itens constantes na métrica. 


\begin{tabular}{|c|c|}
\hline Categorias & Subcategorias \\
\hline \multirow{12}{*}{ Comunidade } & Programas de voluntariado \\
\hline & Patrocínio a projetos de saúde pública \\
\hline & Relações com povos indígenas e quilombolas \\
\hline & Patrocínio a conferências, seminários, exposições ou campanhas \\
\hline & $\begin{array}{l}\text { Doações de recursos para entidades de utilidade pública ou Organização da Sociedade Civil de } \\
\text { Interesse Público (Oscip) }\end{array}$ \\
\hline & Apoio à educação \\
\hline & Apoio à habitação e à alimentação \\
\hline & Apoio à cultura \\
\hline & Apoio a atividades esportivas \\
\hline & Relacionamento com Stakeholders \\
\hline & Decisões ou multas relacionadas à comunidade na qual opera \\
\hline & Investimentos de caráter social \\
\hline \multirow{5}{*}{ Diversidade } & Número de mulheres e/ou minorias na força de trabalho \\
\hline & Ocupação de mulheres e/ou minorias em cargos gerenciais \\
\hline & Proporção de salário base entre homens e mulheres \\
\hline & Contratação de pessoas com deficiência \\
\hline & Não discriminação contra minorias \\
\hline \multirow{5}{*}{$\begin{array}{l}\text { Produtos, serviços e } \\
\text { consumidores }\end{array}$} & Programas de qualidade - International Organization for Standardization (ISO)s 9.000 e 9.001 \\
\hline & Inovação de produtos (Pesquisa \& Desenvolvimento) \\
\hline & Produtos de acordo com as normas de segurança \\
\hline & Satisfação ou insatisfação do consumidor \\
\hline & Concorrência desleal ou práticas de truste \\
\hline \multirow{18}{*}{$\begin{array}{l}\text { Relação com } \\
\text { empregados }\end{array}$} & Número de funcionários, tempo de serviço na empresa e faixas etárias \\
\hline & Remuneração dos funcionários (média e/ou total) \\
\hline & Relações sindicais ou com órgãos de classe \\
\hline & Programas de incentivo à cultura \\
\hline & Desenvolvimento de atividades recreativas e esportivas \\
\hline & Educação e treinamento dos funcionários \\
\hline & Saúde, higiene e segurança no local de trabalho \\
\hline & Acidentes de trabalho, doenças ocupacionais, absenteísmo e óbitos \\
\hline & Aposentadoria e planos de previdência complementar \\
\hline & Auxílio à creche e bolsa de estudos para filhos de funcionários \\
\hline & Suporte à maternidade e à paternidade \\
\hline & Participação nos lucros \\
\hline & Taxa de rotatividade e política de demissão \\
\hline & Participação dos trabalhadores nas decisões gerenciais \\
\hline & Satisfação profissional e motivação dos funcionários \\
\hline & Trabalho infantil, trabalho forçado ou análogo ao escravo \\
\hline & Investimentos em desenvolvimento gerencial \\
\hline & Valor adicionado por empregado \\
\hline
\end{tabular}

Figura 1. Métrica usada para medir a Divulgação Voluntária Social

Fonte: Rover e Santos, 2013. 
O universo desta pesquisa foram as empresas de capital aberto listadas na BM\&FBOVESPA nos períodos de 2010 a 2012. A amostra foi composta pelas 100 empresas listadas na BM\&FBOVESPA com as ações mais negociadas durante os doze meses do ano de 2012. A definição da amostra foi fundamentada pela metodologia do índice de negociabilidade da BM\&FBOVESPA, que possibilita determinar as empresas com as ações mais líquidas em termos de negociação no mercado de capitais. É importante mencionar que os dados necessários para obter o índice de negociabilidade foram extraídos do sistema Economática.

Após a obtenção dos índices de negociabilidade, as empresas foram classificadas em ordem decrescente de acordo com o índice de negociabilidade. Na sequência procederam-se às seguintes etapas: (i) escolha das 139 empresas com ações mais negociadas; (ii) filtraram-se as empresas que possuíam mais de um tipo de ação entre as 139 da etapa (i), considerando apenas um tipo de ação para eliminar duplicidade de empresas, também foram filtradas as empresas holding (optou-se por filtrar as empresas que possuem como objeto social administrar a participação em outras sociedades, visto que essas organizações podem administrar empresas que já estão inclusas na pesquisa); (iii) foram incluídas na amostra apenas empresas que publicaram ao menos um relatório anual de sustentabilidade e/ou balanço social entre 2010 e 2012 . A totalidade de empresas por período está representada na Figura 2.

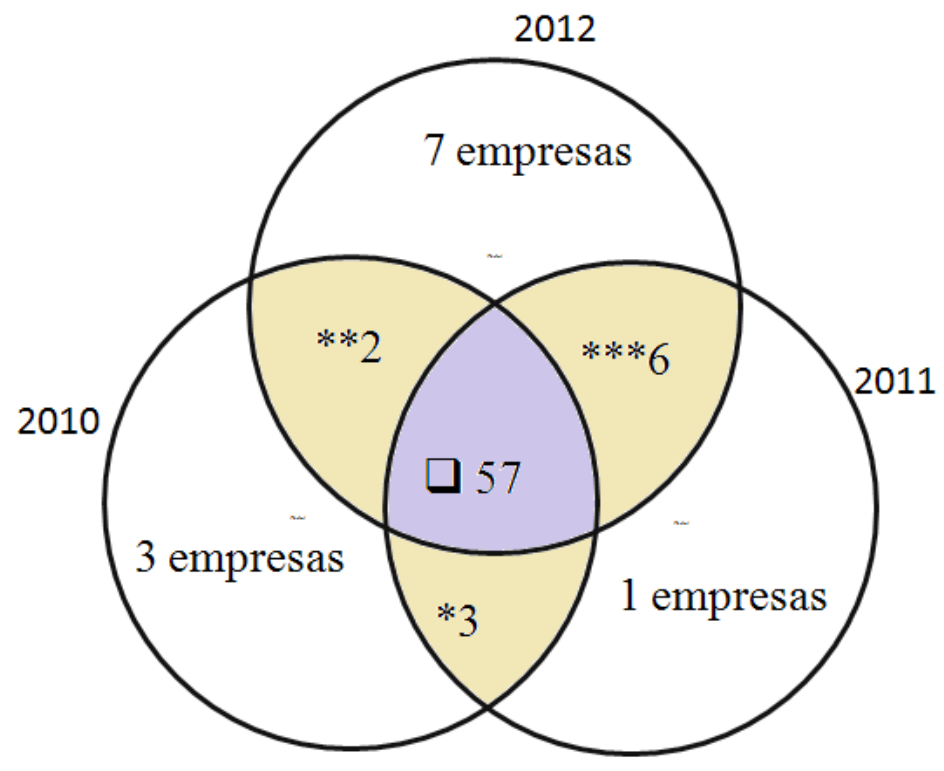

* Empresas que publicaram
relatórios em 2010 e 2011.

** Empresas que publicaram relatórios em 2010 e 2012.

*** Empresas que publicaram relatórios em 2011 e 2012.

\section{$\square$ Empresas que publicaram relatórios em 2010,2011 e 2012 .}

Figura 2. Empresas que compuseram a amostra durante os anos de 2010, 2011 e 2012

Fonte: elaboração própria, 2014.

As observações utilizadas no estudo foram oriundas de duas dimensões, que combinaram dados de corte transversal e dados de série temporal (três períodos - 2010 a 2012). Para definir a melhor especificação do modelo, foram seguidas as seguintes rotinas: estimaram-se o modelo de pooled Ordinary Least Squares (OLS) (OLS agrupado) e os efeitos fixos para testar, por meio do teste de Chow, a hipótese nula de que modelo de pooled OLS é preferível ao modelo de efeitos fixos. Posteriormente, testou-se o modelo para efeitos aleatórios, via teste multiplicador de Lagrange de Breusch-Pagan, o qual verificou a hipótese nula de que o modelo de pooled OLS é preferível ao modelo de efeitos aleatórios. A terceira rotina consistiu em avaliar, pelo teste de Hausman, a hipótese nula de que o estimador de efeitos aleatórios é preferível ao estimador de efeitos fixos, por ser consistente e eficiente. 
Os modelos econométricos foram os descritos na sequência. A Equação 2 refere-se à variável a ser explicada - İndice de Divulgação Social (IDS) - e seus possíveis fatores explicativos (Tamanho, Concentração Acionária, Rentabilidade, Leverage, Setor Regulado e Reputação).

$$
\mathrm{IDS}_{\mathrm{it}}=\alpha+\beta_{1} \mathrm{TAM}_{\mathrm{it}}+\beta_{2} \mathrm{CON}_{\mathrm{it}}+\beta_{3} \mathrm{ROE}_{\mathrm{it}}+\beta_{4} \mathrm{LEV}_{\mathrm{it}}+\beta_{5} \mathrm{REG}_{\mathrm{it}}+\beta_{6} \mathrm{REP}_{\mathrm{it}}+\varepsilon_{\mathrm{it}}
$$

A validação dos pressupostos admitidos pelo modelo de regressão foi executada por intermédio dos seguintes testes: análise de multicolinearidade (Variance Inflation Factor (VIF) e tolerance; avaliação da independência dos resíduos (teste de Durbin-Watson e teste Breusch-Godfrey); estimativa do pressuposto de distribuição normal dos resíduos (teste de Jarque-Bera e teste de Kolmogorov-Smirnov); investigação da homocedasticidade (teste de Breusch-Pagan-Godfrey e teste de White).

\section{Apresentação e Análise dos Resultados}

\subsection{Análise da Estatística Descritiva}

Antes da apresentação e discussão da análise inferencial dos dados, a Tabela 1 expõe os índices médios de divulgação das empresas, por categorias. Essa tabela apresenta os valores médios de divulgação das empresas por categorias, que foram analisadas. Das 12 categorias analisadas, 4 foram referentes à divulgação voluntária social e 9 à divulgação voluntária ambiental. Quanto às subcategorias, foram analisados os contextos de 40 itens sobre divulgação voluntária social e 40 itens acerca da divulgação voluntária ambiental. Sobre isso, constatou-se que não houve uma discrepância acentuada entre as médias das 4 categorias que trataram sobre a divulgação voluntária social.

Tabela 1

Índices médios de divulgação das empresas por categorias

\begin{tabular}{lccccccc}
\hline \multirow{2}{*}{ Categorias } & Quantidade de & \multicolumn{2}{c}{ Média de 2010 } & \multicolumn{2}{c}{ Média de 2011 } & \multicolumn{2}{c}{ Média de 2012 } \\
\cline { 3 - 9 } & subcategorias & $\mathbf{N}^{\circ}$ & $\%$ & $\mathbf{N}^{\circ}$ & $\%$ & $\mathbf{N}^{\circ}$ & \% \\
\hline & \multicolumn{2}{c}{ Índice de divulgação voluntária social } & & & \\
\hline Comunidade & 12 & 6,0923 & 50,77 & 6,4925 & 54,10 & 6,0833 & 50,69 \\
\hline Diversidade & 5 & 2,8000 & 56,00 & 2,9254 & 58,51 & 3,0000 & 60,00 \\
\hline Produtos, serviços e consumidores & 5 & 2,1080 & 42,16 & 2,1343 & 42,69 & 2,1944 & 43,89 \\
\hline Relação com empregados & 18 & 7,9690 & 44,27 & 7,9254 & 44,03 & 8,0417 & 44,68 \\
\hline
\end{tabular}

Fonte: dados da pesquisa (2014).

Conforme a Tabela 2, verificou-se que o índice de divulgação social oscilou entre 0,0500 e 0,7750. A média dos índices de divulgação voluntária social foi de 0,4817 , com um desvio padrão de 0,1813 , ou seja, aproximadamente $62 \%$ dos índices de divulgação social encontram-se no intervalo de 0,3004 a 0,6630 . A média da variável CON foi de 0,4784 e o desvio padrão de 0,2378 , indicando que as participações acionárias pertencentes ao principal acionista varia de 0,2406 a 0,7162 entre as empresas. Sobre a variável ROE, verificou-se que o menor e o maior índice foram - $-0,2574$ e 0,4483 , respectivamente, e a média foi de 0,0475 e o desvio padrão de 0,0632 , indicando que os índices de rentabilidade das empresas pesquisadas estão concentrados no intervalo de 0,0157 a 0,1107 . 
Tabela 2

\section{Estatística descritiva das variáveis}

\begin{tabular}{|c|c|c|c|c|c|c|}
\hline \multicolumn{7}{|c|}{ Variáveis contínuas } \\
\hline \multirow{2}{*}{ Variáveis } & \multirow{2}{*}{ Mínimo } & \multirow{2}{*}{ Máximo } & \multicolumn{3}{|c|}{ Medidas de tendência central } & \multirow{2}{*}{$\begin{array}{c}\text { Medidas de dispersão } \\
\text { Desvio padrão }\end{array}$} \\
\hline & & & Média & Mediana & Moda & \\
\hline IDS & 0,0500 & 0,7750 & 0,4817 & 0,4750 & 0,4250 & 0,1813 \\
\hline TAM & 3,7223 & 8,0452 & 5,2023 & 5,0642 & 3,7223 & 0,9141 \\
\hline CON & 0,0014 & 1,0000 & 0,4784 & 0,5026 & 0,5270 & 0,2378 \\
\hline ROE & $-0,2574$ & 0,4483 & 0,0471 & 0,0384 & 0,0493 & 0,0632 \\
\hline LEV & 0,2382 & 0,9392 & 0,5916 & 0,5790 & 0,4000 & 0,1630 \\
\hline \multicolumn{7}{|c|}{ Variáveis nominais } \\
\hline \multicolumn{2}{|c|}{ Variáveis } & \multicolumn{2}{|c|}{ Dummies } & \multicolumn{2}{|c|}{$\mathbf{N}^{\circ}$ de empresas } & $\%$ \\
\hline \multirow{2}{*}{\multicolumn{2}{|c|}{ REG }} & \multicolumn{2}{|c|}{1 - Setor regulado } & \multicolumn{2}{|c|}{79} & 38,73 \\
\hline & & \multicolumn{2}{|c|}{0 - Setor não regulado } & \multicolumn{2}{|c|}{125} & 61,27 \\
\hline \multirow{2}{*}{ REP } & & \multicolumn{2}{|c|}{1 - Boa reputação } & \multicolumn{2}{|c|}{93} & 45,59 \\
\hline & & \multicolumn{2}{|c|}{0 - Caso contrário } & \multicolumn{2}{|c|}{111} & 54,41 \\
\hline \multicolumn{4}{|c|}{ Quantidade de observações } & & & 204 \\
\hline
\end{tabular}

Fonte: dados da pesquisa obtidos do Economática® e dos relatórios anuais e de sustentabilidade (2014).

Quanto às variáveis nominais, estas não possuem valores quantitativos, sendo definidas por categorias ou classificações, sem que haja uma ordenação entre as variáveis. Neste estudo, utilizaram-se duas variáveis nominais: setor regulado e reputação. Ainda analisando a Tabela 2 , sobre a variável setor regulado, percebe-se que 38,73\% das observações pertencem às empresas que são sujeitas a regulamentação específica de organismos governamentais. Na variável reputação, modelada por uma dummy, 45,59\% das observações são de empresas que possuem boa reputação.

\subsection{Análise da divulgação voluntária social (IDS)}

A modelagem econométrica consistiu em um painel de efeitos aleatórios, estimada por OLS. Os dados foram extraídos de três períodos distintos: 2010, 2011 e 2012. Desse modo, para aplicar a melhor especificação do modelo, foram realizados os testes de Chow, Breusch-Pagan e Hausman. Os resultados dos testes defenderam que o modelo de painel de efeitos aleatório é preferível aos modelos de efeitos fixos e pooled. Para avaliar a existência de efeitos individuais, foi realizado o teste de Chow, segundo o qual não foi possível rejeitar a hipótese nula ( $p$-value $=0.9721)$. O teste de Breusch-Pagan revelou que a hipótese nula foi rejeitada, visto que a variância dos resíduos, que reflete as diferenças individuais, foi diferente de zero $\left(\alpha_{u}^{2} \neq 0\right)$. Já o teste de Hausman mostrou ser apropriada a utilização do modelo de efeitos aleatórios ( $p$-value $=0.1674)$. Conforme a Tabela 3, constatou-se que, entre as três hipóteses de especificação do modelo (pooled, efeitos fixos e efeitos aleatórios), o modelo preferível para estimação é o painel de efeitos aleatórios. 
Tabela 3

Resultados dos testes para melhor especificação do modelo: índice de divulgação social

\begin{tabular}{|c|c|c|}
\hline Testes & Hipóteses & Resultados \\
\hline \multirow{2}{*}{ Chow } & HO - O modelo de pooled OLS é preferível ao de efeitos fixos. & \multirow{2}{*}{$p$-value $=0.9721$} \\
\hline & H1 - O modelo de efeitos fixos é preferível ao de pooled OLS. & \\
\hline \multirow{2}{*}{ Breusch-Pagan } & H0 - O modelo de pooled OLS é preferível ao de efeitos aleatórios. & \multirow{2}{*}{$a_{u}^{2} \neq 0\left(a_{u}^{2}=0.0191\right)$} \\
\hline & H1 - O modelo de efeitos aleatórios é preferível ao de pooled OLS. & \\
\hline \multirow{2}{*}{ Hausman } & H1 - O modelo de efeitos aleatórios é preferível ao modelo de efeitos fixos. & \multirow{2}{*}{$p$-value $=0.1674$} \\
\hline & H1 - O modelo de efeitos fixos é preferível ao modelo de efeitos aleatórios. & \\
\hline
\end{tabular}

Fonte: dados da pesquisa (2014).

Para testar a normalidade dos resíduos, foi utilizado o teste de Jarque-Bera, este mostrou que os resíduos possuem distribuição normal. Para verificar se os resíduos são heterocedásticos, foram utilizados os testes de Breusch-Pagan-Godfrey e de White. Os testes preliminares apontaram à ocorrência dessa condição. Foi utilizado o método cross-section White, que estima parâmetros robustos, assumindo a presença de heterocedasticidade, corrigindo a heterocedasticidade dos resíduos. O diagnóstico da ausência de correlação serial foi realizado por meio dos testes de Durbin-Watson e de Breusch-Godfrey. Este último apontou ausência de correção serial dos resíduos. O diagnóstico da multicolinearidade indica ausência de multicolinearidade entre as variáveis independentes.

O modelo foi estimado com seis variáveis. Para avaliar a relação entre o nível de divulgação voluntária social e as variáveis tangentes às características das empresas (tamanho, concentração acionária, rentabilidade, leverage, setor regulado e reputação), foi estimado o modelo de dados em painel com efeitos aleatórios. $\mathrm{O} \mathrm{R}^{2}$ mediu a variação do modelo, que é explicada pelas variáveis. Nota-se que aproximadamente $25 \%$ da variação do índice de divulgação social é explicada pela variação das variáveis estimadas. Do mesmo modo, a significância do p-value (0.0000) da estatística F, no modelo, corrobora que as variáveis independentes usadas demonstraram significância para explicar o índice de divulgação social.

Tabela 4

Resultados das estimativas do modelo de painel com efeitos aleatórios: variável dependente - índice de divulgação social (IDS)

\begin{tabular}{|c|c|c|c|}
\hline Variáveis & $\beta$ & Estatística t & p-value \\
\hline Tamanho & 0.0333 & $\star \star \star 1.8673$ & 0.0677 \\
\hline Concentração acionária & 0.0359 & 0.7296 & 0.4665 \\
\hline Rentabilidade & -0.3157 & $*-2.3856$ & 0.0180 \\
\hline Leverage & -0.0090 & -0.2273 & 0.8204 \\
\hline Setor regulado & 0.1753 & *3.7273 & 0.0003 \\
\hline Reputação & 0.0416 & *2.6510 & 0.0087 \\
\hline Intercepto & 0.2227 & 3.0458 & 0.0026 \\
\hline $\mathrm{R}^{2}$ & & & 0.2480 \\
\hline $\mathrm{R}^{2}$ ajustado & & & 0.2251 \\
\hline Estatística F & & & 10.8286 \\
\hline$p$-value & & & 0.0000 \\
\hline Estatística Durbin-Watson & & & 1.8686 \\
\hline Jarque-Bera & & & 3.2369 \\
\hline$p$-value & & & 0.2002 \\
\hline Quantidade de observações & & & 204 \\
\hline
\end{tabular}

${ }^{*}, * * \mathrm{e}^{* * *}=$ estatisticamente significante no nível de $1 \%, 5 \%$ e $10 \%$, respectivamente.

Nota: Erros-padrão estimados com correção para heterocedasticidade de Whitecross-section.

Fonte: dados da pesquisa (2014). 
A variável "tamanho" buscou verificar se as empresas maiores possuem um nível maior de divulgação voluntária social. As empresas maiores são sujeitas a uma visibilidade mais frequente dos Stakeholders, e os custos para divulgar as informações têm uma menor representabilidade nas empresas. Conforme a Tabela 4, o resultado mostrou uma relação positiva e significativa $(p$-value $=0.0677)$ entre o nível divulgação voluntária social e o tamanho da empresa, modelado pelo ativo total, corroborando os resultados encontrados nas pesquisas de Belkaoui e Karpik (1989), Jennifer Ho e Taylor (2007), Cunha e Ribeiro (2008), Gamerschlag, Möller e Verbeeten (2011) e Lu e Abeysekera (2014).

Quando a propriedade é relativamente difundida, a falta de divulgação aumentaria a assimetria informacional entre a organização e seus acionistas (Brammer \& Pavelin, 2008). A hipótese "concentração acionária" testou a influência do Stakeholder (acionista) sobre a decisão dos gestores por divulgar informações voluntárias de caráter social. Isso sugere que as empresas com menor concentração acionária divulgariam mais informações voluntárias de natureza social do que as empresas com maior concentração acionária. Com os resultados não é possível inferir se diluição acionária afeta a divulgação voluntária social, dado que o p-value foi não significativo no modelo (Tabela 4). Os resultados foram divergentes dos achados de Gamerschlag, Möller e Verbeeten (2011), Lu e Abeysekera (2014).

Os gestores que têm o conhecimento necessário para fazer uma empresa rentável, também possuem o conhecimento e a compreensão sobre sua responsabilidade social. Além disso, essas empresas teriam mais recursos para investir em ações de responsabilidade social. Sendo assim, a hipótese "rentabilidade" verificou se as empresas que apresentam maior rentabilidade divulgam mais informações voluntárias de natureza social do que as empresas com nível mais baixo de rentabilidade. Os resultados descritos na Tabela 4 mostraram uma significância $(p$-value $=0.0180)$ negativa entre o índice de divulgação voluntária social e a rentabilidade das empresas, o que significa dizer que quanto mais rentável é a empresa, menos ela será propensa a divulgar informações sociais. Esse resultado pode ser um indicio que as empresas utilizam a divulgação voluntária social para amenizar os reflexos da baixa rentabilidade.

A teoria dos Stakeholders defende que os gestores são incentivados a divulgar informação sobre os seus programas ou iniciativas específicas a grupos particulares de Stakeholders com poder de influência. Nesse caso, buscou-se verificar a influência do Stakeholder (credores). Desse modo, foi verificado se as empresas, quando possuem menor índice de leverage, tendem a divulgar mais informações voluntárias de natureza social do que as empresas com maior índice de leverage. De acordo com as informações da Tabela 4, os resultados não apresentaram significância estatística $(p$-value $=0.8204)$ entre a divulgação voluntária social e o índice de leverage. Os resultados estão consistentes com os achados de Cunha e Ribeiro (2008) e Jennifer Ho e Taylor (2007).

A variável "setor regulado" buscou verificar se o Stakeholder (governo) exerce influência sobre o nível de divulgação voluntária social por meio da regulamentação, o que significa dizer que as empresas regulamentadas pelo governo divulgariam mais informações voluntárias de caráter social do que as empresas não regulamentadas. A análise dos resultados descritos na Tabela 4 mostra significância estatística $(p$-value $=0.0003)$ positiva, nesse sentido, parece que a regulamentação do governo exerce influência sobre o índice de divulgação voluntária social, sendo, portanto, um dos fatores explicativos da divulgação voluntária social. Esse resultado é coerente com as constatações de Murcia e Santos (2009).

A variável "reputação" buscou verificar se a divulgação voluntária social pode ser influenciada pela boa reputação da empresa na ótica do Stakeholder sociedade. Sendo assim, a hipótese testou se as empresas que possuem melhor reputação divulgariam mais informação voluntária de natureza social do que as empresas que não têm uma boa reputação. A partir da estimativa do modelo (Tabela 4), foi possível concluir que a boa reputação das empresas é um fator determinante de divulgação voluntária social, visto que os resultados demonstram significância $(p$-value $=0.0087)$ positiva entre a divulgação voluntária social e a boa reputação. Desse modo, não é possível rejeitar a perspectiva da teoria dos Stakeholders, segundo a qual a divulgação de informações voluntárias sociais é vista como uma estratégia para gerenciar a percepção dos diversos grupos de interesse que se relacionam com a empresa, neste caso, a sociedade. 
Tabela 5

Síntese dos resultados: variável dependente - índice de divulgação social

\begin{tabular}{clcccc}
\hline Hipóteses & \multicolumn{1}{c}{ Variáveis } & Sinal esperado & Sinal obtido & Significância obtida & Resultados \\
\hline H1 & Tamanho (TAM) & $(+)$ & $(+)$ & Significante & Não rejeita \\
\hline H2 & Concentração acionária (CON) & $(-)$ & $(+)$ & Não significante & Rejeita \\
\hline H3 & Rentabilidade (ROE) & $(+)$ & $(-)$ & Significante & Rejeita \\
\hline H4 & Leverage (LEV) & $(-)$ & $(-)$ & Não significante & Rejeita \\
\hline H5 & Setor regulado (REG) & $(+)$ & $(+)$ & Significante & Não rejeita \\
\hline H6 & Reputação (REP) & $(+)$ & $(+)$ & Significante & Não rejeita \\
\hline
\end{tabular}

Fonte: dados da pesquisa (2014).

A Tabela 5 faz uma síntese dos resultados esperados pelas hipóteses de pesquisa e os resultados efetivamente encontrados. A partir da análise, é possível concluir que as hipóteses H1, H5 e H6 não foram rejeitadas, por se mostrarem positivamente significantes dentro dos modelos estimados. Apesar de a hipótese $\mathrm{H} 3$ ser significativa, esperava-se que o coeficiente tivesse sinal negativo, o que não foi confirmado nos modelos, portanto, rejeita-se a hipótese de pesquisa $\mathrm{H} 3$. Ainda em relação à síntese dos resultados, percebe-se que a hipótese $\mathrm{H} 4$ possui sinal esperado convergente ao sinal obtido, todavia, os resultados não se mostraram significativos. Por fim, a hipótese $\mathrm{H} 2$ possui sinal divergente do esperado e também vivencia resultado não significativo, desse modo, foi rejeitada nesta pesquisa.

\section{Considerações Finais}

O objetivo desta pesquisa consistiu em investigar os fatores determinantes da divulgação voluntária de informações de caráter social das empresas no período de 2010 a 2012. Para tanto, foram formuladas seis hipóteses, que descreveram as características financeiras ou atributos específicos inerentes a cada empresa, como: tamanho, concentração acionária, rentabilidade, leverage, setor regulado e reputação.

Para alcançar o objetivo proposto, realizou-se um estudo teórico-empírico. Os modelos foram estimados em painel não balanceado com efeitos aleatórios. As variáveis dependentes possuem natureza qualitativa, porém foram quantificadas para a obtenção dos índices de divulgação voluntária, e as variáveis independentes possuem tanto natureza qualitativa como quantitativa, devido à utilização de proxies contínuas e categóricas.

Para as empresas analisadas, constatou-se que: o tamanho da empresa, medido pelo ativo total; a rentabilidade, modelada pelo ROE; a reputação, de acordo com o ranking das 100 empresas com melhor reputação da revista Exame; e a regulamentação, empresas sujeitas a regulamentação específica do governo, foram fatores considerados determinantes da divulgação voluntária social.

As hipóteses testadas anteriormente foram fundamentadas por duas teorias: teoria da divulgação voluntária e teoria dos Stakeholders. A teoria dos Stakeholders reconhece a existência de vários Stakeholders que podem ter interesses comuns ou divergentes, sendo, portanto, responsabilidade da empresa gerenciar os interesses contraditórios. Nesta pesquisa, foi verificado que os Stakeholders acionistas e credores não influenciaram o comportamento das empresas, por divulgarem voluntariamente informações sociais e ambientais. Mas os Stakeholders sociedade e governo foram percebidos como indivíduos capazes de influenciar a divulgação voluntária.

A teoria da Divulgação Voluntária postula que a discricionariedade da divulgação pode ser explicada a partir da necessidade das empresas de reduzir a assimetria informacional. No entanto, em todos os modelos estimados, a divulgação variou inversamente à rentabilidade das empresas. $\mathrm{O}$ fato de as empresas menos rentáveis divulgarem mais informações voluntárias pode ser indício de uma tentativa da empresa de desviar a atenção dos stakeholders do desempenho financeiro ou, ainda, uma tentativa de justificar o baixo desempenho financeiro. 
Entretanto, devem ser consideradas algumas limitações na interpretação dos resultados deste estudo, entre as quais: (i) os resultados podem ser sensíveis às proxies utilizadas para mensurar as variáveis, sendo assim, existe a possibilidade da obtenção de outros resultados se as proxies forem diferentes das utilizadas; (ii) os índices de divulgação voluntária social foram obtidos por meio da técnica de análise de conteúdo, que é sensível ao viés de interpretação do pesquisador; e (iii) os dados utilizados para construir a métrica foram pesquisados em relatórios de ambiente não regulamentado, portanto, não é possível assegurar que todas as informações constantes nos relatórios condizem realmente com a realidade da empresa.

Como sugestão para pesquisas futuras recomenda-se pesquisar a divulgação voluntária social em outros meios de divulgação como o site das empresas, relatórios da administração, propaganda, entre outros.

\section{Referências}

Ameer, R. \& Othman, R (2012). Sustainability practices and corporate financial performance: a study based on the top global corporations. Journal of Business Ethics, 108(1), pp. 61-79. doi: 10.1007/ s10551-011-1063-y

Belkaoui, A. \& Karpik, P. G. (1989). Determinants of the corporate decision to disclose social information. Accounting, Auditing \& Accountability Journal, 2(1), pp. 36-51. doi:.org/10.1108/09513578910132240

Braga, J. P., Oliveira, J. R. S. \& Salotti, B. M. (2009). Determinantes do nível de divulgação ambiental nas demonstrações contábeis de empresas brasileiras. Revista Contabilidade UFBA, Salvador, 3(3), pp. $81-95$.

Brammer, S. \& Pavelin, S. (2008).Factors influencing the quality of corporate environmental disclosure. Business Strategy and the Environment, 17(2), pp. 120-136. doi: 10.1002/bse.506

Branco, M. C. \& Rodrigues, L. L. (2008). Factors influencing social responsibility disclosure by portuguese companies. Journal of Business Ethics, 83(4), pp. 685-701. doi: 10.1007/s10551-007-9658-Z

Ceretta, P. S., Barba, F. G.; Kruel, F. C. M. \& Milani, B. (2009). Desempenho financeiro e a questão dos investimentos socioambientais. RGSA - Revista de Gestão Social e Ambiental, Salvador, 3(3), pp.7284. doi:.org/10.5773/rgsa.v3i3.177

Chang, D. \& Kou, L. R. (2008).The effects of sustainable development on firms' financial performance an empirical approach. Sustainable Development, 16(6), pp. 365-380. doi: 10.1002/sd.351

Chih, H. \& Chih, H. \& Chen, T. (2010). On the determinants of corporate social responsibility: international evidence on the financial industry. Journal of Business Ethics, 93(1), pp. 115-135. doi: 10.1007/ s10551-009-0186-x

Choi, J. S. (1999). An investigation of the initial voluntary environmental disclosures made in Korean semi-annual financial reports. Pacific Accounting Review, 11(1), pp. 73-102.

Clarkson, M. E. (1995). A stakeholder framework for analyzing and evaluating corporate social performance. The Academy of Management Review, 20(1), pp. 92-117. doi: 10.5465/AMR.1995.9503271994

Costa, R. S. \& Marion, J. C. (2007) A uniformidade na evidenciarão das informações ambientais. Revista de Contabilidade e Finanças - USP, São Paulo, 43, pp. 20-33.

Cullen, L. \& Christopher, T. (2002). Governance disclosures and firm characteristics of listed Australian mining companies. International Journal of Business Studies, 10(1), pp. 37-58.

Cunha, J. V. A. \& Ribeiro, M. S. (2008). Divulgação voluntária de informações de natureza social: um estudo nas empresas brasileiras. Revista de Administração - Eletrônica, São Paulo, 1(1), art.6.

Dahlsrud, A. (2008). How corporate social responsibility is defined: an analysis of 37 definitions. Corporate social responsibility and environmental management, 15(1), pp. 1-13. doi: 10.1002/csr.132 
Deegan, C., Rankin, M., \& Tobin, J. (2002). An examination of the corporate social and environmental disclosures of BHP from 1983-1997: A test of legitimacy theory. Accounting, Auditing \& Accountability Journal, 15(3), 312-343. doi: org/10.1108/09513570210435861

Dye, R. A. (2001).An evaluation of essays on disclosure and the disclosure literature in accounting. Journal of Accounting and Economics, 32(1), pp. 181-235. doi:10.1016/S0165-4101(01)00024-6

Eugénio, T. (2010). Avanços na divulgação de informação social e ambiental pelas empresas e a teoria da legitimidade. Revista Universo Contábil, Blumenal: FURB, 6(1), pp. 102-118. doi:10.4270/ruc.2010106

Freeman, R. E. (1999).Divergent stakeholder theory.Academy of Management Review, 24(2), pp. 233-236. doi: 10.5465/AMR.1999.1893932

Gamerschlag, R., Möller, K. \&Verbeeten, F. (2011). Determinants of voluntary CSR disclosure: empirical evidence from Germany. Review of Managerial Science, 5(2-3), pp. 233-262. doi: 10.1007/s11846010-0052-3

Hackston, D. \& Milne, M. J. (1996).Some determinants of social and environmental disclosures in New Zealand companies. Accounting, Auditing \& Accountability Journal, 9(1), pp.77-108. DOI: org/10.1108/09513579610109987

Huang, C. \& Kung, F. (2010). Drivers of environmental disclosure and stakeholder expectation: evidence from Taiwan. Journal of Business Ethics, 96(3), pp. 435-451. doi: 10.1007/s10551-010-0476-3

Jennifer Ho, L. \& Taylor, M. E. (2007). An empirical analysis of triple bottom-line reporting and its determinants: evidence from the United States and Japan. Journal of International Financial Management $\&$ Accounting, 18(2), pp. 123-150. DOI: 10.1111/j.1467-646X.2007.01010.x

Kirch, G., Lima, J. B. N. \& Terra, P. R. S. (2012). Determinantes da defasagem na divulgação das demonstrações contábeis das companhias abertas brasileiras. Revista Contabilidade \& Finanças, 23(60), pp. 173-186.

Liu, X. \& Anbumozhi, V. (2009). Determinant factors of corporate environmental information disclosure: an empirical study of Chinese listed companies. Journal of Cleaner Production, 17(6), pp. 593-600. doi:10.1016/j.jclepro.2008.10.001

Lu, Y. \& Abeysekera, I. (2014). Stakeholders power, corporate characteristics, and social and environmental disclosure: evidence from China. Journal of Cleaner Production, 64, pp.426-436. doi:10.1016/j. jclepro.2013.10.005

Magness, V. (2006). Strategic posture, financial performance and environmental disclosure: an empirical test of legitimacy theory. Accounting, Auditing \& Accountability Journal, 19(4), pp.540-563. doi: .org/10.1108/09513570610679128

Martins, G. A.; Theóphilo, C. R. (2009). Metodologia da investigação científica para ciências sociais aplicadas. 2. ed. São Paulo: Atlas, 2009.

Murcia, F. D. \& Santos, A. (2009).Fatores determinantes do nível de disclosure voluntário das companhias abertas no Brasil. Revista de Educação e Pesquisa em Contabilidade. 3(2), pp. 72-95.doi: .org/10.17524/repec.v3i2.68

Nascimento, A. R., Santos, A., Salotti, B. \& Murcia, F. D. (2009). Disclosure social e ambiental: análise das pesquisas científicas veiculadas em periódicos de língua inglesa. Revista Contabilidade Vista \& Revista, Belo Horizonte: UFMG, 20(1), pp. 15-40.

O'Dwyer, B. (2003). Conceptions of corporate social responsibility: the nature of managerial capture. Accounting, Auditing \& Accountability Journal, 16(4), pp. 523-557. doi: .org/10.1108/09513570310492290

Oliveira, J. A. P. (2005). Uma avaliação dos balanços sociais das 500 maiores. RAE-eletrônica, 4(1), art. 2.

Phillips, R., Freeman, R. E. \& Wicks, A. C. (2003). What stakeholder theory is not. Business Ethics Quarterly, p. 479-502. doi:.org/10.5840/beq200313434 
Reverte, Carmelo. (2009). Determinants of corporate social responsibility disclosure ratings by spanish listed firms. Journal of Business Ethics, 88(2), pp. 351-366. doi:10.1007/s10551-008-9968-9

Roberts, R. W. (1992). Determinants of corporate social responsibility disclosure: an application of stakeholder theory. Accounting Organizations and Society, 17(6), pp. 595-612. doi:10.1016/0361-3682(92)90015-K

Rover, S., Borba, J. A. \& Murcia, F. D. (2009).Características do disclosure ambiental de empresas brasileiras potencialmente poluidoras: análise das demonstrações financeiras e dos relatórios de sustentabilidade do período de 2005 a 2007. Revista Contemporânea de Economia e Gestão, 7(1), pp.23-36.

Rover, S. \& Santos, A. (2013). Disclosure socioambiental e custo de capital próprio de companhias abertas no Brasil. Anais da Conferência Interamericana de Contabilidade Socioambiental, Belém, PA, Brasil, 3 .

Rover, S., Tomazzia, E. C., Murcia, F. D. R., \& Borba, J. A. (2012). Explicações para a divulgação voluntária ambiental no Brasil utilizando análise de regressão em painel. Revista de Administração, São Paulo, 47(2), pp. 217-230. doi: 10.5700/rausp1035

Salotti, B. M.; Yamamoto, M. M. (2005). Ensaio sobre a teoria da divulgação. BBR - Brazilian Business Review, v. 2, n. 1, p. 53-70, jan./jun. 2005. doi: .org/10.15728/bbr.2005.2.1.4

Silva, F. A. \& Pinheiro, L. E. T. (2012). Estágio atual de evidenciação e fatores que influenciam o disclosure de informações por segmentos por empresas brasileiras. Revista de Contabilidade e Controladoria, Curitiba: UFPR, 4(3), pp. 78-94. doi: .org/10.5380/rcc.v4i3.29897

Verrecchia, R. (2001). Essays on disclosure. Journal of Accountingand Economics, Amsterdam, 32(1-3), pp..97-180. doi:10.1016/S0165-4101(01)00025-8

Villiers, C. \& Staden; C. J. V. (2006). Can less environmental disclosure have a legitimising effect? Evidence from Africa.Accounting, Organizations and Society, 31(8), pp. 763-78. doi:10.1016/j.aos.2006.03.001

Wang, K. \& Sewon, O. \& Claiborne, M. C. (2008).Determinants and consequences of voluntary disclosure in an emerging market: evidence from China. Journal of International Accounting, Auditing and Taxation, 17(1), pp. 14-30. doi:10.1016/j.intaccaudtax.2008.01.001

Watson, A., Shrives, P. \& Marston, C. (2002). Voluntary disclosure of accounting ratios in the UK.The British Accounting Review, 34(4), pp. 289-313. : doi:10.1006/bare.2002.0213

Wilmshurst, T. D. \& Frost, G. R. (2000). Corporate environmental reporting: a test of legitimacy theory. Accounting, Auditing \& Accountability Journal, 13(1), pp. 10-26. doi.org/10.1108/09513570010316126 